Published as: Van Gordon, W., Shonin, E., Zangeneh, M., \& Griffiths, M.D. (2014). Can mindfulness really improve work-related mental health and job performance? International Journal of Mental Health and Addiction, 12, 129-137.

\begin{abstract}
Work-related mental health issues such as work-related stress and addiction to work impose a significant health and economic burden to the employee, the employing organization, and the country of work more generally. Interventions that can be empirically shown to improve levels of work-related mental health - especially those with the potential to concurrently improve employee levels of work performance - are of particular interest to occupational stakeholders. One such broad-application interventional approach currently of interest to occupational stakeholders in this respect is mindfulness-based interventions (MBIs). Following a brief explication of the mindfulness construct, this paper critically discusses current research directions in the utilization of mindfulness in workplace settings and assesses its suitability for operationalization as an organization-level work-related mental health intervention. By effecting a perceptual-shift in the mode of responding and relating to sensory and cognitive-affective stimuli, employees that undergo mindfulness training may be able to transfer the locus of control for stress from external work conditions to internal metacognitive and attentional resources. Therefore, MBIs may constitute cost-effective organization-level interventions due to not actually requiring any modifications to human resource management systems and practises. Based on preliminary empirical findings and on the outcomes of MBI studies with clinical populations, it is concluded that MBIs appear to be viable interventional options for organizations wishing to improve the mental health of their employees.
\end{abstract}

Key Words: Work-related stress, Work addiction, Workaholism, Workplace wellbeing, Occupational stress, Job Performance, Mindfulness, Meditation, Buddhism 


\section{Work-related mental health and job performance: Can mindfulness help?}

\section{Introduction}

Work-related mental health issues can cost the British economy up to £26 Billion per year (Sainsbury Centre, 2007). The most prevalent and empirically researched complaint is workrelated stress (WRS) that accounts for $40 \%$ of all work-related illness in Great Britain (Health and Safety Executive [HSE], 2012). Approximately 20\% of British adults are stressed as a result of their work (Houdmont, Cox, \& Griffiths, 2011) and 10.4 million working days each year are lost in Great Britain due to WRS (HSE, 2012). A less empirically investigated but equally consequential work-related mental health issue is work addiction (i.e., 'workaholism'). The prevalence of work addiction in Western populations is approximately $10 \%$, although estimates vary considerably according to how the construct is defined as most definitions of workaholism are not based on addiction criteria found in other behavioral addictions (Sussman, Lisha, \& Griffiths, 2011).

There is growing consensus that work addiction is a bone fide mental health issue that for a minority of employees meets all of the qualifying criteria for classification as a behavioral addiction (e.g., Griffiths \& Karanika-Murray, 2012) (i.e., properties of salience, conflict, mood modification, tolerance, withdrawal symptoms, and relapse - see Griffiths’ [2005] components model of addiction). Both WRS and work addiction can lead to serious detrimental health and socioeconomic consequences including somatic illness, (comorbid) psychopathology, (concurrent) addictive behavior (both chemical and behavioral), workrelated injury, mortality, reduced productivity, absenteeism, presenteeism, high staff turnover, unsafe driving, employee compensation claims, burnout, and work-family conflict (e.g., Cox \& Griffiths, 2010; Frone, Barnes, \& Farrell, 1994; Griffiths \& Karanika-Murray, 2012; 
Manocha, Black, Sarris, \& Stough, 2011; Wu, Fox, Stokes, \& Adam, 2012; Shonin, Van Gordon, \& Griffiths, 2014a; Sussman, 2012).

Mindfulness - a form of meditation that derives from Buddhist practice - involves cultivating a full, direct, and active awareness of experienced phenomena that is spiritual in aspect and that is maintained from one moment to the next. The last two decades have witnessed a marked increase of empirical investigation into the applications of mindfulness meditation within public healthcare domains. Indeed, 72\% of UK-based general practitioners believe that patients can improve their health by practicing mindfulness meditation (Mental Health Foundation, 2010). Similarly, certain mindfulness-based interventions (MBIs) have now been advocated by both the (British) National Institute for Health and Care Excellence (NICE) and the American Psychiatric Association (APA) for the treatment of specific forms of depression (APA, 2010; NICE, 2009).

In addition to depression and other mood disorders, MBIs have been shown to be effective in helping treat a broad range of mental health problems and somatic illnesses including anxiety disorders (Chiesa \& Seretti, 2011), problem gambling (de Lisle, Dowling, \& Allen, 2011), schizophrenia-spectrum disorders (Shonin, Van Gordon, \& Griffiths, 2013a, 2013b), anger dysregulation (Singh, Lancioni, Karazia, Winton, Singh, \& Wahler, 2013a), and cancer (Arias, Steinberg, Banga, \& Trestman, 2006). In addition to applications within clinical populations, MBIs have also been shown to facilitate significant improvements in cognitive function and task performance in healthy adults (e.g., Chiesa, Calati, \& Serretti, 2011; Eberth \& Sedlmeier, 2012).

Karanika-Murray and Weyman (2013) have argued that there is scope for transferring protocols for interventions that are demonstrably efficacious in public healthcare contexts into occupational and organizational domains. Accordingly, in the last few years there has 
been growing scientific interest into the applications of mindfulness in the workplace setting. Of particular interest and relevance to occupational stakeholders is the potential of MBIs to concurrently improve work-related mental health and job performance. Following a brief explication of the mindfulness construct, this paper critically discusses current research directions in the utilization of mindfulness in workplace settings and assesses its suitability for operationalization as an organization-level work-related mental health intervention.

\section{The mindfulness construct}

According to Buddhist thought, individuals have a tendency to ruminate about the past and/or rush towards the 'ungraspable' future (i.e., the future is 'ungraspable' because it never materializes - it is always the present) (Shonin, Van Gordon, \& Griffiths, 2014b). The Buddhist teachings explicate that this behavioral trait of 'not being fully present' can corrupt an individual's perception of reality, and relative to a realized mindfulness/spiritual practitioner, it reduces their experience of existence to that of a 'walking corpse' (Shonin et al., 2014b). Thus, mindfulness is traditionally viewed as a means of 'waking-up' from the sleep of 'corpse-like' unawareness so that an individual can begin to observe, experience, and consciously participate in the present moment. Although there is still an absence of consensus in the literature of both Western medicine and psychology as to what defines the mindfulness construct, there is a reasonable degree of accord amongst academicians that mindfulness: (i) is fundamentally concerned with becoming more aware of the present moment, (ii) can (and should) be practiced during everyday activities and not just when seated in meditation, (iii) is cultivated more easily by using a 'meditative anchor' (e.g., observing the breath), (iv) is a practice that requires deliberate effort and (v) is concerned with observing both sensory and cognitive-affective processes. Key areas of discord amongst Western psychologists in terms of an accurate working definition for mindfulness are as follows: 
1. Non-judgemental awareness: The most popular delineation of mindfulness employed in the Western psychological literature is that proposed by Kabat-Zinn who defines mindfulness as "paying attention in a particular way: on purpose, in the present moment, and non-judgmentally" (1994, p.4). Proponents of this definition contend that the term 'non-judgemental' is appropriate because it infers that mindfulness involves the acceptance (i.e., rather than the rejecting or ignoring) of present-moment sensory and cognitive-affective experiences. However, it might also be argued that the term 'nonjudgemental' is too ambiguous because it conceivably implies that the mindfulness practitioner is essentially 'indifferent' and does not seek to discern which cognitive, emotional, and behavioral responses are conducive to ethically-wholesome conduct (Shonin et al., 2014b).

2. Insight generation: In the Western psychological literature, the terms 'vipassana meditation' and 'insight meditation' are often regarded as being synonymous with the term 'mindfulness meditation' (e.g., Bowen et al., 2006; Chiesa, 2010). However, this portrayal of vipassana meditation (and insight meditation) is not consistent with the traditional Buddhist perspective. According to the classical Buddhist literature, vipassana (a Sanskrit word that means 'superior seeing') meditation involves the use of penetrative investigation in order to intuit (for example) the 'non-self', 'non-dual', and 'empty' nature of reality (Dalai Lama \& Berzin, 1997). Therefore, although mindfulness meditation is certainly insight-generating in the sense that it can facilitate an intimacy with the workings of the mind, 'mindfulness meditation' is not 'insight meditation' according to the traditional Buddhist construction.

3. Context for practice: Mindfulness is traditionally practiced in the context of spiritual development. Indeed, within Buddhism, mindfulness is practiced in conjunction with numerous other spiritual practices and is just one aspect (in fact, the seventh aspect) of a 
key Buddhist teaching known as the Noble Eightfold Path (Van Gordon, Shonin, Sumich, Sundin, \& Griffiths, 2013). At its essence, the Noble Eightfold Path elucidates that the successful establishment of mindfulness relies upon a deep-seated understanding of the three root spiritual principles of: (i) wisdom, (ii) meditation, and (iii) ethics (collectively known as 'the three trainings' - Sanksrit: trishiksha). Consequently, there is ongoing scientific debate relating to whether mindfulness needs to be practiced within the wider context of spiritual development (i.e., as opposed to the sole purpose of overcoming a health complaint or for personal and/or career development).

As a spiritual phenomenon, it is probable that certain dimensions of the mindfulness construct will always remain ineffable and only ever fully understood by those individuals who can tap into them on the experiential rather than the academic plane. As such, it is unlikely that an 'absolute' and all-encompassing definition of mindfulness will ever be operationalized. However, in so far as this represents a problem, it can be easily reconciled if academicians are prepared to accept that "the definition of mindfulness will vary depending on whether one is interested in mindfulness from a social, psychological, clinical, or spiritual context, or from the perspective of a researcher, clinician, or a practitioner, and their various combinations” (Singh, Lancioni, Wahler, Winton, \& Singh, 2008, p.661).

\section{Mindfulness in the workplace: Current research directions}

In light of the significant health and economic burden imposed by WRS and addiction to work, various initiatives have been implemented in recent years with the objective of improving levels of work-related wellbeing via the cultivation and enhancement of healthy working environments. Examples are HSE-led schemes such as Management Standards (HSE, 2007) and Health, Work, and Wellbeing (HSE, 2008) - both of which comply with legislative requirements of the 2004 European Framework Agreement on Work-Related 
Stress. Several recent cross-sectional and intervention studies (e.g., Allen \& Kiburz, 2012; Malarkey, Jarjoura, \& Klatt, 2013; Monoacha et al., 2011) have directly or indirectly assessed the extent to which MBIs may present a cost-effective solution for organizations seeking to implement such schemes.

To date, there has been only one cross-sectional study that has explicitly investigated the relationship between dispositional mindfulness and work-related wellbeing among employed individuals (i.e., Allen \& Kiburz, 2012). They found that trait mindfulness was positively correlated with work-life balance, sleep quality, and vitality in parents $(n=131)$ working more than 20 hours per week. These findings are consistent with a randomized controlled trial (RCT) involving 178 full-time employees of non-specified work backgrounds (with approximately 50\% not educated beyond secondary school level) that received meditation and mindfulness training. Meditating participants demonstrated significant reductions compared with the control group in levels of stress and depression-dejection (Monocha et al., 2011). A more recent RCT study found that 186 university employees that practiced mindfulness meditation showed significant increases over controls in levels of dispositional mindfulness (Malarkey et al., 2013). There have also been several controlled intervention studies of individuals employed in caregiver roles (e.g., primary care physicians, nurses, etc.) that indicate mindfulness can reduce: (i) the risk of burnout and improve levels of clientcentered and empathic care (Krasner et al., 2009), (ii) levels of WRS (Warnecke, Quinn, Ogden, Towle, \& Nelson, 2011), and (iii) levels of anxiety and depression (Kang, Choi, \& Ryu, 2009).

Despite increasing prevalence rates for workaholism, there is a paucity of workaholism treatment studies, and clinical guidelines tend to be based on either theoretical propositions (Sussman, 2012) and/or anecdotal reports elicited during clinical practice (e.g., Robinson, 
1998). Indeed, the only published intervention study exploring the effectiveness of meditation for work addiction is a clinical case study conducted by Shonin et al. (2014a). This study presented the case of a director of a blue-chip technology company that, based on scores on the Bergan Work Addiction Scale (Andreassen, Griffiths, Hetland, \& Pallesen, 2012), demonstrated clinically significant improvements in levels of work addiction following completion of an eight-week secular mindfulness intervention called Meditation Awareness Training (Van Gordon et al., 2013). Significant pre-post improvements were also observed for sleep quality, psychological distress, work duration, and work involvement during nonwork hours. However, the single-participant nature of this study significantly limits the generalizability of these findings.

Other related current research directions involve exploring the utility of mindfulness for improving job performance. However, such empirical enquiry is notably underdeveloped (Dane, 2011) and is limited to just a few exploratory studies. One such study was a crosssectional study of 412 Taiwanese technological company workers that found employee meditation/mindfulness experience was positively associated with self-directed learning, organizational innovativeness, and organizational performance (Ho, 2011). The aforementioned MAT case study (i.e., Shonin et al., 2014a) also assessed work performance and found that mindfulness/meditation lead to improvements in employer-rated job performance.

\section{Mechanisms of Action}

The existing conceptualizations of the WRS construct are (in essence) based on an 'exposureenvironmental' model of work stress. In such conceptual models, WRS is invariably operationalized as a function of the extent to which employees are exposed to sub-optimal working conditions (see Edwards Webster, Van Laar, \& Easton, 2008). Examples of such 
conditions are: (i) inadequate support systems, (ii) inflexible working hours, (iii) conflicting demands, (iv) overly-taxing and/or unrealistic deadlines, and (v) low-work autonomy. This operational model of WRS emphasizes the importance of the employee's 'external' work environment (i.e., as opposed to their 'internal' psychological environment). However, this is a different conceptual approach to that utilized in the traditional mindfulness and meditation teachings. From the traditional Buddhist perspective, rather than exact changes to the external work environment, the most effective means of reducing stress (and all other forms of psychological distress) is to modify the 'internal' (i.e., psychological) working environment (Nhat Hanh, 1999).

By facilitating a perceptual-shift in the mode of responding and relating to sensory and cognitive-affective stimuli, the meditator is better positioned to objectify their cognitive processes and to apprehend them as passing phenomena. This manner of transferring the locus of control for stress from external work conditions to internal metacognitive and attentional resources can be analogized as the difference between covering the entire outdoors with leather, versus simply adorning the feet with a leather sole (Santideva, 1997). Therefore, MBIs may be considered as cost-effective organization-level work-related mental health interventions due to them not actually requiring any ('externally-orientated') modifications to human resource management (HRM) systems and practises.

Another important mechanism by which mindfulness is believed to modulate dysphoric mood states (whether work-related or otherwise) is via the cultivation of compassion and self-compassion. Research has shown that mindfulness can lead to a greater awareness of the individual's own suffering and psychological distress, and this helps to embed a greater awareness of the suffering of others (Shonin, Van Gordon, \& Griffiths, 2013c). Accordingly, greater levels of compassion and self-compassion are thought to lead to improvements in 
levels of tolerance, cooperation (e.g., with senior management), and interpersonal skills more generally (Shonin, Van Gordon, Slade, Griffiths, 2013). Related to the increased levels of compassion/self-compassion is the growth in spiritual awareness that is often a consequence of mindfulness practice. Spiritual development has been shown to broaden perspective and induce a re-evaluation of life priorities in individuals that are addicted to work (Shonin et al., 2014a). Although superficially this may appear to contraindicate job performance, a more balanced level of organizational identification is likely to be beneficial for both employees and the organizations they work for.

The acquisition of problematic addictive behaviors, including workaholism, is associated with maladaptive avoidance strategies that individuals often employ when trying to escape from negative affective states such as guilt, depression, and anxiety (Griffiths, 2005; 2013; Griffiths \& Karanika-Murray, 2012). Accordingly, in the context of addiction, mental urges essentially reflect a conscious or sub-conscious wish to modify mood and receive temporary sensory and/or affective gratification. Mechanisms for the ameliorating effect of mindfulness meditation on addictive behavior are based on a phenomenon known as 'urge surfing' (Appel \& Kim-Appel, 2009). Urge surfing refers to the meditative process of adopting an observatory, non-judgemental, and non-reactive attentional-set that helps to instil an understanding that mental urges are effectively transient and impermanent in nature. By understanding that mental urges will arise and subside of their own accord, the meditation practitioner is no longer at the disposal of habitual compulsive responses but can derive contentment by looking to the source of their mental urges (i.e., their own mind) and simply observing such urges as transient mental phenomena.

Breath awareness - a central feature of mindfulness practice - has been shown to moderate extraneous cognitive activity and help reduce autonomic and psychological arousal 
via increases in prefrontal functioning and vagal nerve output (Gillespie, Mitchell, Fisher, \& Beech, 2012). However, it is important to highlight that the use of breath observance in MBIs does not preclude other experiences from entering into the attentional sphere. In essence, the breath is used to help anchor concentration in the 'here and now', and this concentration is most accurately described as one that is of a broad (rather than narrow) attentional aspect (Dane, 2010; Singh et al., 2008). As a consequence, mindfulness permits employees to attend with due attention to whatever tasks they are engaged in, but without becoming so immersed or lost in such tasks that their situational awareness and cognitive functionality is compromised. Accordingly, although present-moment (i.e., mindfulness-based) working styles and future-orientated (i.e., goal-based) working styles appear to involve competing attentional resources, empirical evidence suggests that mindfulness facilitates rather than impairs goal attainment (see Dane, 2010).

\section{Are MBIs viable as work-related wellbeing interventions?}

As has been demonstrated, there is growing interest amongst occupational stakeholders into the applications of mindfulness (and related meditative techniques) in workplace settings. The key strengths of MBIs as work-related mental health interventions are that they are: (i) cost-effective (e.g., an eight-week group MBI comprising one two-hour session per week that is delivered by one mindfulness instructor to 16 employees corresponds to just one instructor hour per employee), (ii) not invasive to the organization (the practice of mindfulness does not necessitate changes to HRM infrastructure), (iii) not invasive to the employee (i.e., there are few reports of adverse effects associated with MBIs), (iv) acceptable to employees from diverse cultural, religious, and education backgrounds (i.e., MBIs are typically delivered in secular format and have been shown to be acceptable for individuals from both ends of the intellectual functioning continuum [e.g., Singh et al., 2013b; Van Gordon et al., 2013]), (v) 
functional as 'on the job' practices (i.e., mindfulness can be practiced whilst engaging in work tasks), and (vi) potentially able to concurrently effectuate improvements in work-related mental health and job performance.

Many of the factors that may impede the operationalization of MBIs within occupational settings are applicable to all organization-level work-related wellbeing interventions. For example, organizations may be reluctant to adopt a strategic approach to employee wellbeing and may see the roll-out of such interventional initiatives as a threat to short-term revenuegeneration. Furthermore, the effectiveness of any human-taught intervention is significantly dependent upon the aptitude of the facilitating instructors. This is particularly relevant for MBIs because it has been argued that there is currently a shortage of suitably experienced mindfulness/meditation instructors that are able to impart an embodied authentic transmission of the mindfulness teachings (Shonin, Van Gordon, \& Griffiths, 2013d). However, based on the preliminary empirical findings outlined here, and on the outcomes of MBI studies with clinical populations, it is concluded that MBIs appear to be viable interventional options for organizations wishing to improve employee levels of work-related mental health. 


\section{References}

Allen, T. D., \& Kiburz, K. M. (2012). Trait mindfulness and work-family balance among working parents: The mediating effects of vitality and sleep quality. Journal of Vocational Behaviour, 80, 372-379.

American Psychiatric Association. (2010). American Psychiatric Association practice guideline for the treatment of patients with major depressive disorder ( $3^{\text {rd }}$ ed.). Arlington, VA: American Psychiatric Publishing.

Andreassen, C. S., Griffiths, M.D., Hetland, J., \& Pallesen, S. (2012). Development of a work addiction scale. Scandinavian Journal of Psychology, 53, 265-272.

Appel, J., \& Kim-Appel, D. (2009). Mindfulness: Implications for substance abuse and addiction. International Journal of Mental Health and Addiction, 7, 506-512.

Arias, A. J., Steinberg, K., Banga, A., \& Trestman, R. L. (2006). Systematic review of the efficacy of meditation techniques as treatments for medical illness. Journal of Alternative and Complementary Medicine, 12, 817-832.

Bowen, S., Witkiewitz, K., Dillworth, T. M., Chawla, N., Simpson, T. L., Ostafin, B. D., ... Marlatt, G. A. (2006). Mindfulness meditation and substance use in an incarcerated population. Psychology of Addictive Behaviours, 20, 243-347.

Chiesa, A. (2010). Vipassana meditation: Systematic review of current evidence. Journal of Alternative and Complementary Medicine, 16, 37-46.

Chiesa, A., \& Serretti, A. (2011). Mindfulness based cognitive therapy for psychiatric disorders: A systematic review and meta-analysis. Psychiatry Research, 187, 441-453. 
Chiesa, A., Calati, R., \& Serretti, A. (2011). Does mindfulness training improve cognitive abilities? A systematic review of neuropsychological findings. Clinical Psychology Review, 31, 449-464.

Cox, T., \& Griffiths, A. (2010). Work-related stress: A theoretical perspective. In: Leka, S., \& Houdmont, J., (Eds.). A textbook of occupational health psychology: 31-56. Oxford: Wiley-Blackwell.

Dalai Lama, \& Berzin, A. (1997). The Gelug/Kagyu tradition of mahamudra. New York: Snow Lion Publications.

Dane, E. (2010). Paying attention to mindfulness and its effects on task performance in the workplace. Journal of Management, 37, 997-1018.

de Lisle, S. M., Dowling, N. A., \& Allen, J. S. (2011). Mindfulness and problem gambling: A review of the literature. Journal of Gambling Studies. doi:10.1007/s10899-011-9284-7.

Eberth, J. \& Sedlmeier, P. (2012). The effects of mindfulness meditation: A meta-analysis. Mindfulness, 3, 174-189.

Edwards, J. A., Webster, S., Van Laar, D., \& Easton, S. (2008). Psychometric analysis of the UK Health and Safety Executive’s Management Standards work-related stress Indicator Tool. In: British Academy of Management Annual Conference, 10-12 Sep 2008, Harrogate, UK.

Frone, M., Barnes, G., \& Farrell, M. (1994). Relationship of work-family conflict to substance use among employed mothers. Journal of Marriage and the Family, 56, 10191030. 
Gillespie, S. M., Mitchell, I. J., Fisher, D., \& Beech, A. R. (2012). Treating disturbed emotional regulation in sexual offenders: The potential applications of mindful selfregulation and controlled breathing techniques. Aggression and Violent Behavior, 17, 333343.

Griffiths, M. D. (2005). A 'components' model of addiction within a biopsychosocial framework. Journal of Substance Use, 10, 191-197.

Griffiths, M. D. (2013). Social networking addiction: Emerging themes and issues. Journal of Addiction Research and Therapy, 4, e118, doi: 10.4172/2155-6105.1000e118

Griffiths, M. D., \& Karanika-Murray, M. (2012). Contextualising over-engagement in work: Towards a more global understanding of workaholism as an addiction. Journal of Behavioural Addictions, 1, 87-95.

Health and Safety Executive. (2007). Managing the causes of work-related stress. A step-bystep approach using Management European Approaches to work-related stress. Nottingham (UK): Author.

Health and Safety Executive. (2008). Improving health and work: Changing lives. Available from: http://www.dwp.gov.uk/docs/hwwb-improving-health-and-work-changing-lives.pdf. (Accessed 24 ${ }^{\text {th }}$ December 2013).

Health and Safety Executive. (2012). Stress and psychological disorders. Available from: http://www.hse.gov.uk/statistics/causdis/stress/index.htm. (Accessed $24^{\text {th }}$ December 2013).

Ho, L. (2011). Meditation, learning, organisational innovation and performance. Industrial Management and Data Systems, 111, 113-131. 
Houdmont, J. Cox, T., \& Griffiths, A. (2011). Work-related stress case definitions and prevalence rates in national surveys. Occupational Medicine, 60, 658-661.

Kabat-Zinn, J. (1994). Wherever you go, there you are: Mindfulness meditation in everyday life. New York: Hyperion.

Kang, Y. S., Choi, S. Y., \& Eunjung, R. (2009). The effectiveness of a stress coping program based on mindfulness meditation on the stress, anxiety, and depression experienced by nursing students in Korea. Nurse Education Today, 29, 538-43.

Karanika-Murray, M., \& Weyman, A. K. (2013). Optimising workplace interventions for health and wellbeing: A commentary on the limitations of the public health perspective within the workplace health arena. International Journal of Workplace Health Management, 6, 104-117.

Krasner, M. S., Epstein, R. M., Beckman, H., Suchman, A. L., Chapman, B., Mooney, C. J., \& Quill, T. E. (2009). Association of an educational program in mindful communication with burnout, empathy, and attitudes among primary care physicians. Journal of the American Medical Association, 302, 1284-1293.

Manocha, R., Black, D., Sarris, J., \& Stough, C. (2011). A randomised controlled trial of meditation for work stress, anxiety and depressed mood in full-time workers. EvidenceBased Complementary and Alternative Medicine, DOI:10.1155/2011/960583.

Malarkey, W. B., Jarjoura, D., \& Klatt, M. (2013). Workplace based mindfulness practice and inflammation: A randomized trial. Brain, Behaviour and Immunity, 27, 145-154. 
Mental Health Foundation. (2010). Be mindful report. Availiable from: http://www.mentalhealth.org.uk/publications/be-mindful-report/ $\quad$ Accessed $7^{\text {th }}$ January 2014).

National Institute for Health and Care Excellence (NICE). 2009. Depression: Management of depression in primary and secondary care. London: Author.

Nhat Hanh, T. (1999). The heart of the Buddha's teaching: Transforming suffering into peace, joy and liberation. New York: Broadway Books.

Robinson, B. E. (1998). The workaholic family: A clinical perspective. American Journal of Family Therapy, 26, 65-75.

Sainsbury Centre for Mental Health. (2007). Mental health at work: Developing the business case. London: Author.

Santideva. (1997). A guide to the Bodhisattva way of life. (V. A. Wallace, \& A. B. Wallace, Trans.) New York: Snow Lion Publications.

Shonin, E., Van Gordon, W., \& Griffiths, M. D. (2014a). The treatment of workaholism with Meditation Awareness Training: A case study. Explore: The Journal of Science and Healing, in press.

Shonin, E., Van Gordon, W., \& Griffiths, M. D. (2014b). The emerging role of Buddhism in clinical psychology: Towards effective integration. Psychology of Religion and Spirituality, in press. 
Shonin, E., Van Gordon, W., \& Griffiths, M. D. (2013a). Do mindfulness-based therapies have a role in the treatment of psychosis? Australia and New Zealand Journal of Psychiatry, doi: 10.1177/0004867413512688.

Shonin, E., Van Gordon, W., \& Griffiths, M. D. (2013b). Cognitive Behavioral Therapy (CBT) and Meditation Awareness Training (MAT) for the treatment of co-occurring schizophrenia with pathological gambling: A case study. International Journal of Mental Health and Addiction, doi: 10.1007/s11469-013-9460-3.

Shonin, E., Van Gordon W., \& Griffiths M. D. (2013c). Meditation Awareness Training (MAT) for improved psychological wellbeing: A qualitative examination of participant experiences. Journal of Religion and Health, doi: 10.1007/s10943-013-9679-0.

Shonin, E., Van Gordon, W., \& Griffiths, M. D. (2013d). Mindfulness-based interventions: Towards mindful clinical integration. Frontiers in Psychology, 4, 1-4, doi: 10.3389/fpsyg.2013.00194.

Shonin, E., Van Gordon W., Slade, K., \& Griffiths, M. D. (2013). Mindfulness and other Buddhist-derived interventions in correctional settings: A systematic review. Aggression and Violent Behavior, 18, 365-372.

Singh, N. N., Lancioni, G. E., Karazia, B. T., Winton, A. S. W., Singh, J., \& Wahler, R. G. (2013a). Shenpa and compassionate abiding: Mindfulness-based practices for anger and aggression by individuals with schizophrenia. International Journal of Mental Health and Addiction, doi: 10.1007/s11469-013-9469-7. 
Singh, N. N., Lancioni, G. E., Winton, A. S. W., Karazia, B. T., Singh, A. D. A., Singh, A. N. A., \& Singh, J. (2013b). A mindfulness-based smoking cessation program for individuals with mild intellectual disability. Mindfulness, 4, 148-157.

Singh, N. N., Lancioni, G. E., Wahler, R. G., Winton, A. S., \& Singh, J. (2008). Mindfulness approaches in cognitive behavior therapy. Behavioral and Cognitive Psychotherapy, 36, 659-666.

Sussman, S. (2012). Workaholism: A review. Journal of Addiction Research and Theory, Suppl 6: 4120, doi: 10.4172/2155-6105.S6-001.

Sussman, S., Lisha, N., \& Griffiths, M. D. (2011). Prevalence of the addictions: A problem of the majority or the minority? Evaluation and the Health Professions, 34, 3-56.

Van Gordon, W., Shonin, E., Sumich, A., Sundin, E., \& Griffiths, M. D. (2013). Meditation Awareness Training (MAT) for psychological wellbeing in a sub-clinical sample of university students: A controlled pilot study. Mindfulness, doi: 10.1007/s12671-012-01915.

Warneke, E., Quinn, S., Ogden, K., Towle, N., \& Nelson, M. R. (2011). A randomized controlled trial of the effects of mindfulness practice on medical student stress levels. Medical Education, 45, 381-388.

Wu, T., Fox, D., Stokes, C., \& Adam, C. (2012). Work-related stress and intention to quit in newly graduated nurses. Nurse Education Today, 32, 669-74. 